Vol. 5, No. 3, 2019

\title{
FISCAL STRATEGY AS AN INSTRUMENT OF ECONOMIC GROWTH*
}

\author{
Igor Chugunov ${ }^{1}$, Valentina Makohon ${ }^{2}$
}

\begin{abstract}
The purpose of the article is to justify the role of the fiscal strategy in ensuring macroeconomic stability and accelerating the pace of economic growth, disclose and substantiate its key objectives in the developed and transformational economies. The comparative and factor method allowed revealing the essence and role of the fiscal strategy as an instrument of economic growth, identifying peculiarities and substantiating approaches to the management of uncertainty of fiscal strategies, revealing the principles of the formation of the fiscal strategy and medium-term budget planning in Ukraine. Methodology. The substantiation of the role of the fiscal strategy in ensuring macroeconomic stability and accelerating the pace of economic growth, and definition of its key objectives are based on the generalization and systematization of the experience of countries with a developed and transformational economy. For this purpose, the analysis and evaluation of the fiscal policy were made, the peculiarities of the formation and implementation of fiscal strategies in the corresponding countries were determined. Results have shown that in developed countries, the GDP gap concept is used in order to use fiscal policy for countercyclical purposes. Budget sustainability is characterized by the ability of state and local government bodies to timely and fully finance budget expenditures and to support the share of budget deficits and public debt in the gross domestic product at an economically sound level. Budgetary stability is the constancy of budget architectonics in time. The essence of budget architectonics is the optimal ratio of budget, tax, social, monetary, and public debt components of the fiscal policy, which is a dynamic institutional process of its development and implementation in the relevant socio-economic conditions of the country's development. At an appropriate level of budget stability, the level of fiscal burden on the economy does not increase. Fiscal equilibrium - consistency of budget revenues and expenditures. Practical implications. The benchmark of the fiscal strategy in terms of economic transformations should be to ensure macroeconomic stability and accelerate the pace of economic growth by increasing the soundness of budget architectonics. Value/originality. Strengthening the influence of endogenous and exogenous factors on the financial and economic environment of the state, and negative demographic tendencies on the development of society necessitate the development of a fiscal strategy as a dynamic self-organizing one with a fractal dimension and scale, the system of long-term financial and economic measures, goals, principles, directions, tasks that are implemented by public administration, in a multiaspect dimension: budget transformations, configurations of fiscal institutions, socio-economic transformations. The fractal dimension implies the formation of a system of long-term financial and economic measures, goals, principles, directions, tasks of the country's fiscal policy based on the subsystems of the fiscal policy of regions with similar features, which will provide an opportunity to ensure consistency of actions of state authorities and local self-government bodies, constituents of the fiscal policy. The validity of the fiscal strategy determines the level of effectiveness of socio-economic transformations. In terms of economic transformations, budget architectonics, the institutional features of its formation are becoming increasingly difficult to assess in both developed and transformational economies.
\end{abstract}

Key words: public finance, fiscal strategy, budget architectonics, budget deficit, public debt.

JEL Classification: E62, H60, O40

\footnotetext{
Corresponding author:

${ }^{1}$ Kyiv National University of Trade and Economics, Ukraine.

E-mail: chugunov055@gmail.com

ORCID: http://orcid.org/0000-0003-4915-1267

${ }^{2}$ Kyiv National University of Trade and Economics, Ukraine.

E-mail:makvknteu@gmail.com

ORCID: http://orcid.org/0000-0002-2331-8455
}

\footnotetext{
*The article is prepared on the basis of materials of RW "Budget strategy of economic growth" (state registration number 0118U000128).
} 


\section{Introduction}

In modern conditions, the fiscal strategy plays a significant role in regulating economic processes, taking into account their dynamism and cyclicality. The need to develop and increase the validity of the fiscal strategy is conditioned by transformations in the economic environment, which actualize the issue of predicting financial opportunities for their implementation and assessing the risks of violations of budget stability associated with the processes of deepening financial integration and increasing negative demographic trends in society.

The importance of developing a fiscal strategy is fully understood both in countries with developed and transformational economies. Government documents define strategic tasks for the development of the budget system, directions for coordinating its components in the short, medium, and long term.

A fiscal strategy is a powerful tool for influencing macroeconomic stability and accelerating economic growth. Its effectiveness is determined by the level of maintenance of long-term sustainability, stability, and balance of the budget system. At the same time, the forms of manifestation of fiscal instability are a violation of the interconnections in the system of capital turnover, as evidenced by the processes: the formation of consumption funds at the expense of fixed and working capital; strengthening of speculative aspects in the turnover of capital, which is reflected in its outflow from the production sphere to the trade and intermediary and financial and credit; the incapability of public authorities to effectively influence monetary circulation and the system of bank settlements, which prevents the continuity and stability of the capital turnover; failure to ensure full and timely payments in the vertical and horizontal planes of the budget system. Thus, the research problem is as follows: what is the role of the fiscal strategy in providing macroeconomic stability in the context of economic transformations, which its key areas will contribute to accelerating economic growth? This article aims to reveal the features of the formation and implementation of fiscal strategies in developed and transformational economies, to generalize, systematize, and substantiate their strategic directions in the context of economic transformations.

\section{The essence and role of the fiscal strategy}

The fiscal strategy is dynamic, capable of selforganization, has a fractal dimension and scale of the system of long-term financial and economic measures, goals, principles, directions, tasks implemented by public administration, in a multidimensional dimension: budget transformations, configurations of fiscal institutions, socio-economic transformations.

The fractal dimension implies the formation of a system of long-term financial and economic measures, goals, principles, directions, tasks of the country's fiscal policy based on the subsystems of the fiscal policy of regions, with similar features, which will provide an opportunity to ensure consistency of the actions of state authorities and local self-government bodies, constituents of the fiscal policy.

Strategic directions of fiscal strategies are the basis for developing effective practical measures to ensure budget sustainability, stability, and balance, which contributes to accelerating the pace of economic growth. Budget sustainability is characterized by the ability of state and local government bodies to timely and fully finance budget expenditures and to support the share of budget deficits and public debt in the gross domestic product at an economically sound level. Budget stability is the constancy of budget architectonics in time. The essence of budget architectonics is the optimal ratio of budget, tax, social, monetary, and public debt components of the fiscal policy, which is a dynamic institutional process of its development and implementation in the relevant socio-economic conditions of the country's development. At an appropriate level of budget stability, the level of fiscal burden on the economy does not increase. Fiscal equilibrium - consistency of budget revenues and expenditures.

The development of the fiscal strategy allows: on the basis of the key tasks of socio-economic development of the country, to evaluate the necessary financial resources for their solution and to determine the main sources of their obtaining; to make sound, rational decisions based on their future impact assessment; to take into account probable trajectories of development of fiscal relations proceeding from the development of new programs, reforms, legislative acts; to identify in a timely manner the methods and instruments of fiscal policy necessary for achieving the goals set; to evaluate adverse trends and risks of violation of budget sustainability, stability, balance and justify preventive measures.

When substantiating the fiscal strategy, important tasks are to take into account the institutional features, trends and cycles of economic processes without losing the unity of goals and objectives of the development of the system of public finances in general.

\section{Features of fiscal strategies in developed countries}

As foreign experience shows, the effectiveness of fiscal strategies depends on the reasonableness of choosing methods and tools for budget projection and planning, and the quality of assessing the efficiency of public financial resources in terms of economic and functional classification. In particular, in the countries of the European Union, considerable attention is paid to public financing of innovations as a key component for sustainable economic growth, long-term competitiveness of countries. At present, the Horizon 
2020 program is designed to finance innovation (about 80 billion euros), which consists of the following areas: Excellence Science; Industrial Leadership; Societal Challenges; Spreading Excellence and Widening Participation; Science with and for Society; European Innovation Council (EIC) Pilot; Focus areas; European Institute of Innovation and Technology; Euratom (Horizon 2020, 2018). The role of the social function of the fiscal policy aimed at raising the level of public welfare through budget support of healthcare and pension insurance is increasing (Table 1).

Table 1

Main demographic and macroeconomic assumptions (baseline scenario in \% of GDP)

\begin{tabular}{|l|c|c|c|c|c|c|}
\hline & 2020 & 2030 & 2040 & 2050 & 2060 & 2070 \\
\hline $\begin{array}{l}\text { Real potential GDP } \\
\text { (growth rate) }\end{array}$ & 1,4 & 1,2 & 1,2 & 1,4 & 1,5 & 1,4 \\
\hline Healthcare costs & 6,9 & 7,2 & 7,4 & 7,6 & 7,7 & 7,7 \\
\hline State pensions & 11,1 & 11,6 & 12,0 & 11,7 & 11,3 & 11,0 \\
\hline
\end{tabular}

Source: developed by the author according to the data: The 2018 Ageing Report (2018)

Of great importance in ensuring budget stability in the European Union countries are: European Financial Stability Facility; European Stability Mechanism; European Financial Stabilization Mechanism.

In order to determine the level of impact of potential imbalances on budget sustainability, stability, and balance, these institutions use a wide range of indicators. If indicators show the existence or predictability of imbalances in a particular country of the European Union, an in-depth analysis of macroeconomic and fiscal indicators is carried out in order to determine the degree of risk, as well as recommendations for solving the identified problems are provided. The key parameters of fiscal sustainability in the long term include economically justified indicators: external imbalance; share in the gross domestic product: budget deficit, state and commercial debt, credit flows in the non-government sector, international assets, export market; the level of labour expenditures per unit of output; exchange rate fluctuations; annual increase in real estate prices; unemployment rate.

In accordance with the legislation, countries of the European Union develop long-term fiscal projects, which are based on the assessment of the efficiency and effectiveness of public financial resources, their influence on the country's socio-economic development in the process of projecting their distribution. When developing projects, economic and mathematical models based on fiscal rules are used. At the same time, several scenarios of budget indicators are developed, including baseline one based on the expected rates of economic development. At the supposed negative gap of the gross domestic product, incentive measures of the fiscal policy are considered reasonable, at positive one - restrained, which allows minimizing the negative impact of the downward economic trend. In particular, with a negative gap of the gross domestic product, the level of budget revenues reduces due to a lower volume of production and, consequently, a decrease in the level of receipts from income tax, a lower volume of consumption and, consequently, a decrease in the level of VAT revenues.

The study of the experience of the European Union countries has made it possible to identify the peculiarities of the formation and implementation of fiscal strategies: strategic directions are necessarily published in official mass media, accordingly, the principle of openness and transparency is ensured; the justification of directions is based on taking into account the interests of all participants in the budget process; strategies necessarily include: the analysis and comparison of the foreseen financial situation with the past, the main problems of ensuring budget sustainability, stability, and balance, and expected changes in the development of the economic environment are revealed; strategies include an assessment of the impact of possible measures of the fiscal policy in the foreseeable future on the country's socio-economic development; strategies determine the goals, priorities, tasks of the fiscal policy and possible ways of their implementation; strategies include an assessment of the impact of macroeconomic and demographic factors on budget stability.

It is important to note that fiscal strategies in developed countries are largely aligned with countries' socioeconomic development programs, and projections of their tasks in the short-term and medium-term budget planning are provided. In conditions of economic transformations, attention is paid to the evaluation of uncertainty of fiscal strategies since the effectiveness of the uncertainty management mechanism determines the level of achievement of their goals.

\section{Uncertainty management approaches}

The uncertainty of the fiscal strategy is associated with a significant level of volatility of income, interest rates, negative effects of factors that determine global demand, natural disasters, political decisions, and the amplitude of exchange rate fluctuations.

Among the approaches to managing uncertainty, it is expedient to distinguish between: conservative budget projections, according to which key budget parameters are projected conservatively, so the real budget execution may be better than previously laid in budgets; central reserves, according to which the definition of a budget reserve at an economically justified level creates the necessary margin for budget sustainability and stability in the conditions of increasing the negative impact of exogenous or endogenous factors. It is determined that a sufficient amount of budgetary reserves contributes to the development of the investment environment; the 
establishment of a margin consisting of reserves defined by the Ministries, from which technical or political adjustments to budget expenditures may be financed; the exclusion of volatile expenditures from the mediumterm and long-term budget planning limits.

It is worth pointing out that the spending limits can be determined in real or nominal terms. As a rule, determining the nominal terms for the current year creates a reliable basis for budget planning. Establishing limits in real terms for future years can provide a better basis for planning in the event of high and volatile inflation rates. When making decisions on setting limits in real terms, the fiscal impact is taken into account. At the same time, the creation of a budget reserve is considered to be justified. In particular, in New Zealand, in the budget projection process, the budget reserve, which is allowed to be recalculated in case of changes in economic conditions, is taken into account but changes in the limits of new costs that may be covered by the next annual budget are not allowed. By limiting the new political initiatives that can be taken, at the same time, it does not place the actual costs in the rigid boundaries in case of a deterioration of the indicators of the country's economic development. In Austria, there is a model that provides for significant deviations from the limits and gives the government agencies the opportunity to underspend the allocated funds. Fixed expenditures in Austria make up $75 \%$ of total expenditures. The reserve of funds for unbudgeted expenditures is about $0.5 \%$ of expenditures for the budget year with an increase of approximately $2 \%$ over the medium term. The reserve is not allocated between the ministries and is provided to compensate for technical adjustments, rather than to finance new political initiatives.

\section{Ukraine's fiscal strategy}

According to the Strategy for Sustainable Development "Ukraine 2020", the importance of substantiating the strategic directions of the fiscal policy in the medium and long term is determined; it is justified that the important task is not only to develop priorities but also the mechanisms for their implementation, define specific time frames for achieving key macroeconomic and fiscal indicators; the selectivity and timeliness of decisions of the fiscal policy and its components will reduce to zero economic growth and increase socio-economic tension in society; the strategic goal is to fulfil the Maastricht convergence criteria, in particular, regarding price stability, budget deficit, public debt, stability of national currency and interest rates (On the Strategy for Sustainable Development “Ukraine 2020", 2015).

An important condition for ensuring the acceleration of economic growth is the development of an integrated and harmonized program for reforming the system of public finances in the medium and long-term perspective, including the substantiation of effective mechanisms for its implementation, in accordance with the Strategy for Public Finance Management System Reform for 2017-2020. The key objectives of this Strategy are to create conditions for the full implementation of strategic budget planning, ensuring the strategic distribution of public financial resources (On Approval of the Strategy for Public Finance Management System Reform for 2017-2020, 2017). At the same time, in Ukraine, the fiscal strategy as a separate strategic document is not developed.

At the present time, issues of full implementation of the medium-term budget planning in the budget process were actualized. An important task in this direction is to ensure a clear link between the formation of budgets of different levels and their implementation in the medium term. At the same time, the basis for a full-fledged introduction of medium-term budget planning is to provide a reliable source base for macroeconomic and fiscal indicators. In order to evaluate the initial base, it is necessary to understand well the budget architectonics and the factors of its formation. Herewith, it is appropriate to develop a methodology for evaluating the components of budget architectonics. To this end, it is necessary to carry out a qualitative analysis of budget execution in previous years; to determine the methodology for assessing the impact of macroeconomic parameters on budget indicators, which will enable to optimize the procedure for updating the source base.

Also, an important task is to ensure the uniformity of the budget execution process, which envisages: provision of the opportunity to use the appropriations released at the beginning of the fiscal year; preparation of ministries for the budget execution during the last quarter of the previous year; the possibility of allocating budgetary appropriations based on a plan prepared before the beginning of the fiscal year; settlement of transfer of budget commitments to the next year.

The possibility to spend over-planned revenues will allow avoiding changes in the budget balance; however, this is not necessarily optimal for medium-term budget planning since over-revenues are mostly worthwhile saving. Herewith, this may increase the budget volatility, which will increase the level of expenditures for the coming years.

It is worth pointing out that the "use or lose" concept can stimulate inappropriate spending at the end of the year. At the same time, unlimited transfers of unused funds create a risk of significantly exceeding the aggregate limits and reduce the ability to perform fiscal target indicators and objectives in subsequent years. In particular, in Austria, departments received the right not to return unused funds, which led to a significant accumulation of reserves, the use of which to achieve the target budget indicators is practically not allowed. In France, no more than 3\% of expenditures are allowed to be transferred. In Ireland - not more than $2 \%$, while in the range of $2 \%$ to $6 \%$ it is allowed to transfer $2 / 3$ of unused budgetary appropriations. 
The experience of developed and transformational economies shows that the development of a fiscal strategy contributes to ensuring the effectiveness of the system of public finances in general, and creates a basis for raising the level of responsibility of public authorities for achieving the strategic goals of socio-economic development of countries.

\section{Conclusions}

The fiscal strategy plays a significant role in the system of state regulation of economic processes, as it provides an opportunity for a timely and well-balanced assessment of the influence of exogenous and endogenous factors on budget parameters, sustainability, stability, and balance of the budget system. The development of the fiscal strategy contributes to strengthening the overall fiscal discipline and consistency of the fiscal policy with the strategic goals of socio-economic development of the country based on an integrated combination of long-term directions and tasks of state authorities and local self-government and justifies the ways of their implementation. The basis of the budget strategy is the system of long-term financial and economic measures, goals, principles, directions, tasks that are implemented by the public administration in a multiaspect dimension based on the features of social development of the country, the level of economic development, cyclicality and dynamism of economic processes. The achievement of the strategic goals of the country's development depends on the degree of consideration in the budget strategy of development trends in the institutional environment of the fiscal space, the effectiveness of the mechanisms used to manage uncertainty in the budget sphere. At the same time, an important task in the context of economic transformations is to implement prudent fiscal policy on the basis of the justification of the total budget expenditures and the assessment of fiscal risks. Based on the experience of developed economies, the development of a fiscal strategy in countries with a transformational economy should be based on: the projected prospect of socio-economic development of countries; ensuring consistency of the indicators of short-term, medium-term, and long-term budget planning; development of the base budget on the basis of evaluation of various options of the fiscal policy; assessment of the impact of exogenous and endogenous factors on budget sustainability, stability, and balance.

In conditions of economic transformation, budget architectonics, the institutional features of its formation are becoming increasingly difficult to assess in both developed and transformational economies. The benchmark of the fiscal strategy in terms of economic transformations should be to ensure macroeconomic stability and accelerate the pace of economic growth by increasing the soundness of budget architectonics. At the same time, the development of a fiscal strategy is only a prerequisite for ensuring macroeconomic stability and accelerating the pace of economic growth. It is advisable to ensure its feasibility, reasonableness, and the effectiveness of the ways of implementation. Disclosure of these issues requires further scientific research.

\section{References:}

European Financial Stability Facility. Retrieved from: https://www.esm.europa.eu/

European Financial Stability Mechanism. Retrieved from: https://www.esm.europa.eu/

European Stability Mechanism. Retrieved from: https://www.esm.europa.eu/

Horizon 2020 (2018). Work Programme 2018-2020. European Commission Decision C, 4708: 39.

The 2018 Ageing Report (2018). Economic and Budgetary Projections for the EU Member States (2016-2070). Institutional paper 079: 406.

Pro Stratehiiu staloho rozvytku "Ukraina - 2020" (2015). [On the Strategy for Sustainable Development “Ukraine - 2020”]. Ukaz Prezydenta Ukrainy 12.01.2015, 5/2015. Retrieved from: http://zakon.rada.gov.ua/laws/show/5/2015

Pro skhvalennia Stratehii reformuvannia systemy upravlinnia derzhavnymy finansamy na 2017-2020 roky (2017). [On Approval of the Strategy for Public Finance Management System Reform for 2017-2020]. Rozporiadzhennia Kabinetu ministriv Ukrainy 08.02.2017, 142-p. Retrieved from: https://www.kmu.gov.ua/ua/npas/249797370 